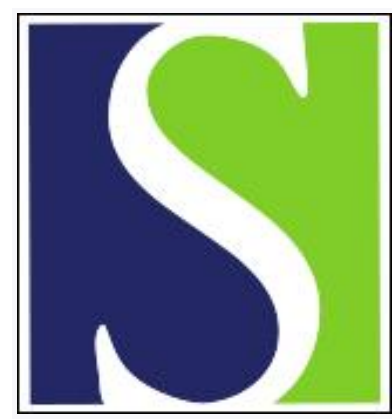

Scand J Work Environ Health 2018;44(4):436-438

https://doi.org/10.5271/sjweh.3746

Published online: 02 Jun 2018, Issue date: 01 Jul 2018

Scientific basis of the OCRA method for risk assessment of biomechanical overload of upper limb, as preferred method in ISO standards on biomechanical risk factors

by Colombini $D$, Occhipinti $E$

Affiliation: Scientific Association "Ergonomics of Posture and Movements International Ergonomics School" (EPM IES), Milan Italy. epmies.corsi@gmail.com

Refers to the following text of the Journal: $2018 ; 44(3): 323-329$

The following article refers to this text: $2018 ; 44(4): 439-440$

Key terms: biomechanical overload; biomechanical risk factor; ISO standard; Letter to the Editor; OCRA method; risk assessment

This article in PubMed: www.ncbi.nlm.nih.gov/pubmed/29961081 


\section{Scientific basis of the OCRA method for risk assessment of biomechanical overload of upper limb, as preferred method in ISO standards on biomechanical risk factors}

We are writing in regards to Armstrong et al's recent discussion paper (1), which addresses the scientific basis of ISO standards on biomechanical risk factors and more specifically the OCRA methodology. The paper comments on the ISO's working methods, but it will be up to the ISO to respond if it sees fit to do so. As the authors of the OCRA method, we wish to respond in a individual capacity. For several years, we have belonged to an ISO working group (ISO TC 159/SC3/WG4) advocating methods for the assessment of biomechanical overload risk; the members of the working group come from various countries and represent public authorities, social partners and researchers with particular expertise in this field.

Our decision to send this letter to the editor was motivated by the following position put forth in Armstrong et al's paper concerning the rigor of development of the ISO ergonomics standards:

"The production of the ISO ergonomics standards differed substantially from the writing of evidence-based practical guidelines. According to the limited information provided in the published documents, the ISO ergonomics standards were not based on a systematic search and appraisal of available literature. It is not clear why the ISO subcommittee preferred one method of risk assessment over others. For instance, the ISO 11228-3 identified three detailed risk assessment methods for repetitive hand exertions at high frequency: OCRA (a concise index for the assessment of exposure to repetitive movements of the upper limbs) (20), ACGIH hand activity level (HAL) (21), and the Strain Index (22), but preferred the OCRA methods without providing a scientific basis or comparison (eg, intra- and inter-observer reliability, strength of association with musculoskeletal disorders (MSD), etc.) even though such comparisons are available in the literature $(13,23)$. As a result, some statements in ISO 11228-3 appear to be based on personal opinions and are in contrast with scientific evidence from the literature. For instance, the ISO standard includes a statement "in many epidemiological surveys it (OCRA) has shown itself to be well related with health effects (such as the occurrence of UL-WMSD [upper limb-work related MSD)]" (13). This statement was not supported by a well-designed epidemiological study in 2007 when the ISO standard was published (19). Indeed, in 2010, Takala and colleagues noted the absence of longitudinal studies on the association between the OCRA index and the risk of MSD. They also pointed out the absence of studies on the repeatability of the OCRA method (13)'. (Note: the references in italic relate to the original paper).

We would like to point out that the ISO standards in question (2) were actually developed by the working group, as mandated by ISO, over the period 2000-2004. The years leading up to the publication of the standard (2005-2007) were dedicated to the challenging task of democratically seeking the endorsement of the ISO member countries. During this time, no significant changes could be made to the basic text other than those arising from specific observations or comments from the countries. This needs to be taken into account, especially when debating the references underpinning the standard.

More specifically, the standard in question (ISO 11228-3) (2) in Annex A, clearly states that the general reference model for assessing "repetitive, high frequency, low load movements of the upper limbs" is a Consensus Document, drafted and published in 2001 by the IEA-Technical Committee on Musculoskeletal Disorders, with the endorsement of the International Commission on Occupational Health (ICOH) (3). The study considered at least 14 different methods that have over time been suggested in the literature as briefly summarized in the same ISO standard (2).

The recommendations set forth in this vital Consensus Document went on to become the basis for choosing the most appropriate methods to suggest to future users through the standard (OCRA; ACGIH Hand Activity Level (HAL); Strain Index), each with their respective merits and limits in compliance with the criteria set out in the Consensus Document and taking into account their applicability in the field and ability to interpret the results of the risk assessment.

It is against this background, and in light of the rationale described in Annex A, that the entire group agreed that the OCRA method was to be considered as the "preferred" method, insofar as it was deemed to best match the recommendations laid out in the aforementioned Consensus Document.

Furthermore the OCRA method was, at the time, the only risk assessment method supported by the results of several epidemiological, albeit cross-sectional studies, uniquely available in literature. The study was based on a very large number of cases ( $>5000$ cases) with results 
both of risk evaluation of upper-limb biomechanical overload (using the OCRA method) and of musculoskeletal clinical examination (assessing the corresponding diseases). Such studies were reported in a special issue of Ergonomics (4), in an updated paper - first published in Italian (5) - also in Ergonomics (6), in the books edited by Elsevier (7), and CRC Taylor \& Francis (8). This risk/damage database enabled an estimation (within defined limits) of the risk of upper-limb workrelated musculoskeletal disorders at a given OCRA index level. Starting from the established relation among risk indexes and percent of pathological subjects, it was possible to determine the risk limit values provided by the ISO standard (2).

With reference to the alleged absence of studies on the repeatability of the OCRA method, we prefer to mention the most recent results obtained by other researchers, rather than our findings, acknowledging the good "inter-rater reliability" of the OCRA Checklist, and stating that "the OCRA Checklist inter-rater reliability scores were among the highest reported in the literature for semi-quantitative physical exposure assessment tools of the upper extremity" (9)

As for the scientific base, we suggest Armstrong et al (1) could get more valuable information about the OCRA methodology looking not only to the 1996 special issue in Italian language (10) - the only publication they mention dealing specifically with OCRA - but to the many updated publications. Some of the most relevant publications in English (as suggested by the publisher) are mentioned in the references here below. Many other publications and manuals in English, Italian, Spanish and Portuguese are available but not reported here due to limitation of space. A complete list of our publications can be found on our website: www.epmresearch.org, where some of the articles are available for download. Simple tools (Excel spreadsheets) for carrying out risk assessments by OCRA can also be freely downloaded from the same website. The validity and usability of OCRA methodology can also be indirectly confirmed by its extensive use around the world. For example, a recent search on ScienceDirect (www.sciencedirect.com/science/journals/all/full-text-access) has recently shown that more than 477 works dealing with OCRA hae been published by different authors in indexed journals to date.

In conclusion, we recommend the authors of the discussion paper (1) deepen their analysis of the OCRA methodology [beyond the only cited old 1996 paper (10)] before expressing definite conclusions about the scientific value of the OCRA methodology and about the entire ISO standard-setting system.

Our team is always happy to engage with the scientific community and end users of studies on biomechanical overload, as we have also done within the ISO for many years now. ISO working groups arguably offer valuable opportunities to come together at the international level and table discussions between researchers and users. We are researchers who have devoted our life's work to prevention, and intend to continue striving towards that goal, with everyone's help and without bickering, bias, vested interests, or professional rivalry. The health and well-being of workers is all we have ever cared about. We have always been ready to cooperate with those who share this vital objective.

\section{References}

1. Armstrong T J, Burdorf I A, Descatha A, Farioli A, Graf M, Horie S, Marras W S, Potvin J R, Rempel D, Spatari G, Takala E P, Verbeek J, Violante FS. Scientific basis of ISO standards on biomechanical risk factors. Scand J Work Environ Health. 2018;44(3):323-329. https://doi.org/10.5271/sjweh.3718

2. ISO. ISO 11228-3. Ergonomics - Manual handling Handling of low loads at high frequency. ISO, 2007. Geneva, Switzerland.

3. Colombini D, Occhipinti E, Delleman D, Fallentin N, Kilbom A, Grieco A. Exposure assessment of upper limb repetitive movements: a consensus document in W. Karwowski International Encyclopaedia of Ergonomics and Human Factors, New York: Taylor \& Francis, 2001.

4. Colombini D, Grieco A, Occhipinti E. Occupational musculoskeletal disorders of the upper limbs due to mechanical overload. Ergonomics. Special issue;1998:41(9).

5. Occhipinti, E., Colombini, D. Metodo OCRA: aggiornamento dei valori di riferimento e dei modelli di previsione dell'occorrenza di UL-WMSDs nelle popolazioni lavorative esposte a movimenti e sforzi ripetuti degli arti superiori. [The OCRA method: update of UL-WMSDs reference values and prediction models of occurrence in working populations exposed to repetitive movements and strains of the upper limbs]. La Medicina del Lavoro, 2004. 95;4:305-319

6. Occhipinti E, Colombini D. Updating reference values and predictive models of the OCRA method in the risk assessment of work-related musculoskeletal disorders of the upper limbs. Ergonomics; 2007,50(11):1727-1739. https://doi. org/10.1080/00140130701674331

7. Colombini D, Occhipinti E, Grieco A. Risk assessment and management of repetitive movements and exertions of upper limbs. Amsterdam: Elsevier Science, 2002.

8. Colombini D, Occhipinti E. Risk analysis and management of repetitive actions: a guide for applying the OCRA system (occupational repetitive actions). New York: CRC press, 2016.

9. Paulsen R, Gallu T, Gilkey D, Reiser R, Murgia L, Rosecrance J. The inter-rater reliability of Strain Index and OCRA Checklist task assessments in cheese processing. Applied Ergonomics. 2015;51,199-204. https://doi.org/10.1016/j. apergo.2015.04.019 
10. Occhipinti E, Colombini D. Proposal of a concise index for the evaluation of the exposure to repetitive movements of the upper extremity (OCRA index)]. Med Lav. Special issue, 1996 Nov-Dec; 87(6): 526-548

Daniela Colombini, PhD, ${ }^{1}$ Enrico Occhipinti, PhD ${ }^{1}$

${ }^{1}$ Scientific Association "Ergonomics of Posture and Movements International Ergonomics School (EPM IES)", Milan Italy. [epmies.corsi@gmail.com] 